Am. J. Nephrol. 1981;1:223

\title{
Quiz of the Mont
}

\section{Answer to Question 1 and 2}

The correct diagnosis is renal angiomyolipoma, a benign hamartomatous tumor of the kidney. This tumor is rare in the general population but may occur with up to $80 \%$ frequency in patients with tuberous sclerosis, a disease characterized by epilepsy and mental retardation associated with nodular lesions in the brain and the facial lesions of adenoma sebaceum. Pathologically, this tumor is composed of vascular, fatty, and smoth muscle and may be misdiagnosed as a liposarcoma. Although angiomyolipoma is frequently multicentric, this tumor is considered a benign process as neither malignant change nor metastases have been demonstrated. Radiologic features of this tumor are marked radiolucency on plain films due to high lipid content and multiple small arterial aneu-rysms without arteriovenous shunting on angiography. However, as in our patient, diagnostic radiologic features may be absent giving an appearance similar to renal cell carcinoma.

\section{References}

McCullough, D.L., Scoot, R., Jr.; Seybold, H.M.: Renal angiomyolipoma: review of the literature and report of seven cases. J. Urol. 105: 32-44 (1971).

Farrow, G.M.; Harrison, E.G., Jr.; Utz, D.C.; Jones, D.R.: Renal angiomyolipoma: a clinicopathologic study of 32 cases. Cancer 22/564-570(1968).

Silberger, M.L.; Peterson, C.C.: Renal angiomyolipoma: its distinctive angiographic characteristics. J. Urol. 106: 363-365 (1971).

Answer to Question 2

This is a case of mixed metabolic acidosis and alkalo-sis. The metabolic alkalosis is the result of severe and prolonged vomiting. Its presence is reflected by the urine chloride concentration of 1 $\mathrm{mEq} / 1$ and a plasma chloride concentration of $46 \mathrm{mEq} / 1$. The high anion gap metabolic acidosis is the result of a combination of factors. The patient was markedly volume contracted; volume contraction resulted in severe organ under perfusion. This is, in part, reflected by the severe prerenal azotemia. The combination of tissue under perfusion and hypoxia, the result of chronic and acute pulmonary disease, doubtless resulted in the generation of excess lactic acid. It is also possible that this patient had ketonemia. The finding of no ketones in the urine does not exclude this possibility. In the presence of tissue hypoxia the ratio of reduced to oxidized NAD will increase and ketones, should they be present, be converted from acetoacetate to beta-hydroxybutyrate. This latter salt does not react with the standard laboratory tests for ketones. Thus, the severe anion gap acidosis present in this patient was likely the result of the accumulation of sulfate and phosphate owing to severe renal underperfusion, to the generation of excess lactate, and possibly to ketonemia as well. The loss of acid from the stomach negated the gain of acid from tissue hypoxia so that the blood $\mathrm{pH}$ was normal.

Following the infusion of large amounts of salt and water the patient's BUN and creatinine fell within $72 \mathrm{~h}$ to 20 and $0.9 \mathrm{mg} / \mathrm{dl}$, respectively. During this period his bicarbonate concentration increased to $35 \mathrm{mEq} / 1$ and his arterial $\mathrm{pH}$ rose to 7.51 . This was doubtless the result of metabolism of the salts of weak organic acids to bicarbonate. This finding further suggests the 
presence of excess lactate and ketone bodies. When the patient had recovered he stated that he had been drinking a fifth of bourbon daily and that he had been vomiting for the 2 weeks prior to admission. In summary, this is a severe case of mixed metabolic acidosis and alkalosis due to vomiting and tissue hypoxia.

References

Kurtzman, N.A.; Arruda, J.A.L.; Westenfelder, C.L.: Gastric alkalosis. Contr. Nephrol., vol. 14, pp. 155-161 (Karger, Basel 1978).

Ritz, E.; Heidland, A.: Lactic acidosis. Clin. Nephrol. 7: 231-240 (1977). 